\title{
CIVIC SOCIETY'S INTERVENTION ON PEASANTRY AGRICULTURE IN RURAL ZIMBABWE
}

\author{
Mafongoya Owen, Lecturer \\ Great Zimbabwe University, Zimbabwe \\ E-mail: omafongoya@gmail.com
}

\begin{abstract}
The study investigated the contribution of SAT's agricultural intervention in ward 21 of Bikita in an attempt to improve food security to this drought prone area. The research was largely premised on qualitative methodology and unstructured interviews, focus group discussions and onsite observation were employed as techniques for data gathering. Using these methodological techniques, it was revealed that conservation farming brought by SAT was not smoothly appreciated by the intended beneficiaries. Regardless the fact that the majority of the farmers were given free farming inputs, they failed to fully embrace all the instructions like minimizing soil tillage, reliance on compost manure only to mention but a few. The farmers resisted total participation because the techniques were labor intensive and sometimes contradict their orthodox or indigenous farming techniques. This has resulted in the emergence of an antagonistic relationship between SAT officials and the local farmers on the best method of farming which may improve food security. Also the research revealed that too much reliance on compost manure has created environmental challenges with fears of its depletion since the area was already overpopulated. This led to the emergence of conflicts between the participants, non-participants, owners and non-owners of domestic animals because the forage was under threat. All these events were analyzed using Darendorf's (1959)'s Conflict theory which explains the potential of conflicts outbreak between two or more groups interacting. This can be best explained with the conflicts which existed between the locals on the environment and also between SAT and the locals on the way forward about farming. It was concluded that there was a need for encompassing approach where all stakeholders should sit down together and consider the favorable conditions to make the programme acceptable, successful and sustainable.
\end{abstract}

\section{KEY WORDS}

Conservation farming; Induced participation; Philanthropisim; Beneficiaries; Subordination; Superodination.

Agriculture has emerged to be the economic backbone of most African nations. It is the foundation for people's survival as well as the major contributor to socio-economic prosperity. The economies of most developing countries especially those in Sub-Saharan Africa are largely agro-based and there is overreliance on the natural environment. In these countries, 'development' and 'industrialization' has remained minimal, survival in rural areas is largely hinged on peasantry subsistence farming and other primary production activities. Subsistence farming activities in most rural areas of Sub-Saharan Africa are largely characterized by less application of advanced technology which may contribute in boosting the yields in farming enterprise. The use of simple tools like hoes, shovels, picks, ploughs only to mention but a few is dominant in subsistence farming. On the same platform, these farming equipments are labor intensive. Most of these agricultural activities are usually carried out in areas characterized with unfertile soils and precarious climatic conditions were rainfall patterns are mostly unpredictable, ephemeral and scarce. This explains that, the majority of such rural farmers are exposed to perennial hunger. This can be evidenced by Tichivangani (2008)'s observations in Masvingo where he expressed that for the past five years, the rural farmers have been facing acute household food insecurity. These pronounced food insecurities are believed to be necessitated by several trends such as weather variability (climatic changes), bio-diversity degradation, high inflation rates, political instability, and additional pressure also emanating from skyrocketing population growth. On the same sentiments, Ackerman (2009) expressed that the world was undergoing hard times of climate change caused by global warming hence posing a severe threat to humanity. The 
increasing heating of the earth's surface will negatively affect production especially agriculture and this makes the earth an unfriendly habitat. Mintz (1995) explained that people in these regions are not only exposed to hunger alone, but it creates serious barriers for people with plummeting economies and facing ever increasing exposure to diseases, fatigue and decreased concentration in most important live endeavors. This explains that challenges like poverty and hunger are on the increase since most of them over depend on dry land or rain fed farming with minimized application of irrigation techniques in endeavor to overcome perennial droughts. This makes agriculture a backbreaking exercise and also an unreliable enterprise regardless of it being the cornerstone of human survival. To cushion the avalanche of shortcomings associated with growing of crops, the majority of subsistent farmers practiced mixed farming where they also keep domestic animals like sheep, goats, chickens, cattle, donkeys among others. However, the handicap with the domestication of these animals is that they won't be sufficient enough to take care of their owners' day to day needs like food and money for other basic needs like clothes, school fees, among others. Overally, the unification of these agricultural techniques has proved to be less successful and this has broadened the clientele base to suffering. After facing all the challenges like perennial droughts, poverty and vulnerability, it emerged that the rural farming enterprise has become the laboratory for intrusions and intervention by outsiders like governments, agronomists, politicians, and civic society among others. Attached to the intervention is the aspect of experimentation brought in by the outsiders. In most developmental interventions, it has been noted that problems has been erupting between the beneficiaries and donors pertaining to the management of the overall project. Thus the crux of this study is to unveil whether the philanthropic agricultural interventionist stances by SAT have yielded positive or negative effects in improving and sustaining subsistence agricultural activities in ward 21 of Bikita. The research also unveiled the acceptability of the project by the local farmers as well as power dynamics which exists between the interveners and the intended beneficiaries.

Studies have revealed that both rain-fed cultivation and pastoral activities has dominated the Zimbabwean economy despite contributing only $15-20$ percent of the total Gross National Product, (Rukuni, Eicher and Blackie, 2006). Despite critics by academics and other technocrats that this percentage is too insignificant be recognized, some positive thinkers tended to differ and they appreciated its role because it takes charge for the survival of the majority of the unemployed rural populace. To further buttress these positive thinking, Rukuni etal (2006) propounded that subsistence agriculture in rural areas provides both food and a steady income which cover up to $75 \%$ of the needs of two million people in Zimbabwe. This reveals that the majority of the people in the countryside rely much on farming as bedrock for rural livelihoods. However, the whole farming exercise is largely affected by adverse climatic conditions in the Sub-Saharan Africa. Makwara (2010) espoused that Zimbabwe is divided into five agro-ecological regions. In this realm, Bikita district under Masvingo province lies in region four characterized by unreliable, erratic and insufficient rainfall patterns. This therefore calls for a rational and innovative response to these impediments affecting the local people's livelihoods. In the same vain, there might also be strong desire to engage outside world for ideas and assistance which may cushion the poverty stricken peasantry people out of vulnerability and suffering. Some agronomists, social commentators and other academic think-tanks have suggested for the implementation of irrigation techniques to supplement the unreliable and insufficient rainfall patterns. Despite irrigation appearing to be the panacea to the challenges confounded by the poor rural farmers, severe financial shortages thwarts the efforts to kick start vibrant irrigation projects. That being the case, these brilliant strategies remain a dream far away from the ever expecting and impoverished beneficiaries.

After having faced acute challenges with subsistence farming and lacking of irrigation opportunities, the rural farmers also heavily relied on outside intervention especially from the civic society. The civic society usually provides free food handouts and other basics like clothing to the vulnerable people. However, some social thinkers have propounded that it is noble to give a man fish but it is best to teach him how to fish so that he may feed himself and his family forever. In the same line of thinking, Makwara (2010) observed the great need for the consideration of conservation farming which is preached and supported by many Non- 
Governmental Organizations (NGOs) in Zimbabwe as a solution to make hunger a thing of the past. He further argues that conservation farming initiatives if they are properly followed they become a panacea in improving agricultural output in those regions characterized by precarious agro-ecological climatic conditions. Ellis (2000) espoused that conservation farming is not a new phenomenon but was introduced in the past three decades and was adopted in more than fifty countries. He further espoused that it is roughly estimated that the area under conservation farming stretched over hundred million hectares of land worldwide. Those that call for the adoption and implementation of conservation farming praised it much on zero tillage or minimized tampering with the soil. The avoidance of tilling the land is considered as advantageous in curbing the purported high rate of soil disturbance which promotes rampant soil erosion, increasing planting lines as well as lengthening harvest timelines. In this line of argument, Gukurume, etal (2010) also espoused that conservation farming has been credited by its prime movers for its ability to increase soil organic matter which implies the creation of better soil structure and increased nutrients sufficient for plant growth. Conservation farming has also been praised for being economically friendly to the less privileged rural farmers for instance zero tillage implies zero costs for most of the activities in the farming process. This implies that even the people with no draught power would manage to harness valuable yields for their survival. Despite conservation farming being applauded as the panacea in improving yields in adverse agro-ecological conditions, Makwara (2010) expressed that this initiative is not uniform to every people but they may be the best in mainly disadvantaged populations. He further stresses that it is as a prime target for the poorest and desperate farmers who are also supported with farm inputs such as seed maize, fertilizer among others. He narrated that in Hurungwe, the rural farmers has received and participated in conservation with high levels of enthusiasm. This has also contributed immensely in improving food security in the area which was once affected by severe droughts and food insecurity. Makwara (2010) further stated that Hurungwe farmers have expressed happiness with conservation farming and they no longer rely on food handouts from Non-governmental Organizations (NGOs). This therefore explains that conservation farming in Hurungwe has become an antidote for the dire food insecurity conditions which has been experienced by the local people in the previous decades.

Whilst some scholars, agronomists and farmers have preached a successful experience with conservation farming, it emerged that its acceptability was not the same everywhere. This explains that some people in other areas perceive this initiative as backbreaking exercise with minimized benefits. Studies by Gukurume etal (2010) has revealed that in Chivi district of Masvingo province, conservation farming introduced by CARE International and ACTION FAIM was not successfully appreciated by the intended beneficiaries. The farmers interpreted the exercise as blatantly reverting to the orthodox developmental model of top-down approach characterized by 'induced' participation. On the same stance, Kasam (2010) reiterated that conservation farming has been resisted in some areas because some practices like zero tillage tended to contradict their orthodox ways farming which they have experienced for the past years. Some farmers resisted zero tillage arguing that they have enough draught power and other farming implements which makes their work easier if compared to this intensive labor demanding exercise. Rural farmers in Chivi as observed by Gukurume etal (2010) reiterated that they believe in winter ploughing which is usually done at least two times before the final planting of crops. Their point of argument is that this exercise would allow their soil to be free and to receive air as well as mixing up the soil sometimes with cattle manure. That being the case, total eradication tilling the land replaced by perennial digging would complicate the whole farming process. Gukurume etal (2010) further noted that the rural farmers in Chivi stated that the 'dhiga udye' (dig and survive) phenomenon would be converted into 'dhiga ufe' (dig and die). This implies that the local people perceive the exercise as a death knell to their health as well as their farming carriers.

Arguing from the above observations, conservation farming has appeared to have different flavors if put across different areas and regions in Zimbabwe. In the case of Bikita district, CARE International has been the renounced promoter of this new farming mechanism. They gave people maize seeds and fertilizer and thereafter people were 
encouraged and also trained to practice zero tillage accompanied with digging using hoes. After the failure to attract attention from the farmers, CARE International withdrew from the project paving way for SAT to take over this new farming project. This therefore becomes the pinnacle of this study to unveil if there are similarities or differences in approaches employed by these two organizations in their efforts to cushion the rural people out of severe droughts. The research weighed SAT's contribution to food security and the livelihoods of people of ward 21. In this regard, people's perceptions and appreciation is solicited whether SAT is the messiah to the perennial food woes which had haunted the district for the past decades. Thereafter, an introspection was made on the aspect of the sustainability of the project as compared to the one previously introduced by CARE International.

\section{THEORETICAL FRAMEWORK}

In this study, the researcher mainly utilized Darendorf's (1959)'s conflict theory in analyzing the obtained data. The analysis will be greatly impinged on his three main concepts which are super ordination, subordination and conflicts. As the point of departure, Darendorf (1959) envisaged that social structure and unit of analysis are essentially voluntary associations of people who share certain values and set up institutions in order to ensure the smooth functioning of co-operation. He further stated that in every social organization, some positions are entrusted with legitimate power and the right to exercise control over other positions in order to ensure effective coercion. Those with power will dominate those without power who will automatically become the subordinates. Taking these sentiments closer to the study, it can be observed that in the farming enterprise in ward 21 , there is a voluntary association between SAT as an organization and the local farmers both with the ambition of making food insecurity a thing of the past. In this scenario, SAT officials are emerging to have the upper hand in this union basing on the fact that they are technocrats as compared to the majority of uneducated rural farmers. Aiding to the above advantage, SAT officials also get an upper hand because they are the once who own and control the resources to kick-start conservation farming. This explains that they will be at the greater advantage of determining how this new farming technology should be executed and in return, the beneficiaries are also to religiously follow. Darendorf (1959) further stated that the existence of dominant and subordinate positions produces a situation in which individuals have different interests. Those in subordinate positions like the local farmers in this case have interest in changing the social structure which deprives them of authority and control in the execution of the new farming technologies. The relationship between these two categories characterized by diametrically opposed life worlds led to unhealthy social relations which has some debilitating influence to the total success of conservation farming. In this realm, SAT officials as the dominant or superordinate take the advantage of being resourced and made the local farmers to submit to their instructions and interests. However, since human beings are rational and calculative, the local people will not subject themselves to entirely new farming methods which they did not understand or which contradicts their indigenous knowledge. After the farmers observed that the new farming recommendations were not friendly to them and overburden them, they objected and this created an antagonistic relationship between the two groups. This explains that the intervention by SAT has opened floodgates for contestations and struggles pertaining to how should the programme should be run. At some point in time too much of these tensions may be detrimental to the achievement of the targeted and predicted goals.

\section{METHODOLOGICAL ORIENTATION}

This study was premised on the qualitative paradigm in soliciting valuable information about conservation farming brought by SAT in ward 21 of Bikita. This has been made easy by the use of research instruments like unstructured interviews and Focus Group Discussions and onsite observation in the fields. Mwanje (2001) espoused that the qualitative approach has been praised by people because for its subjectiveness, flexibility and descriptive. That being the case unstructured interviews and FDGs helped much in exploring 
how the farmers have responded to new farming initiatives by SAT. Through the use of these techniques, people have expressed their perceptions, attitudes, emotions and reaction to the new farming technologies. Through question and answer segments during the research process, people explored their sentiments about acceptability and the sustainability of the project in the agricultural enterprise. On the very note, two SAT field officers were considered as key informants. They deliberated vital information with regards to their activities and how they relate with the beneficiaries citing the positive and negative benefits they are encountering in the process. To compliment people's expressions about the project, the researcher walked into some fields of participants observing how they are complying with SAT's new farming technologies. In the selection of respondents, purposive sampling was utilized. The researcher was not concerned about other variables like sex among others but targeted all the farmers both participants and non-participants but domiciling in ward 2. This helped much in supplying important information about the new farming methods. It is also worth to note that the purposively selected respondents have not been coerced to participate in the study and there was consensus.

\section{PRESENTATION AND DISCUSSION OF FINDINGS}

Contestations over new farming methods. From the study carried out in ward 21 of Bikita, it has emerged that agriculture is the only source of survival at the same time it is also back breaking exercise which has never been a simple since time immemorial. The coming in of donor agencies has caused a lot of complexities in the farming enterprise in rural Bikita. During the study, it was noted that before the coming in of SAT with conservation farming initiatives, there was CARE international which failed to attract the local farmers into these conservation farming. The local people and these philanthropic organizations were always at loggerheads pertaining to new farming instructions like zero tillage. To make matters worse, the farmers were encouraged to venture into intensive digging of holes where they can plant their seeds, looking for manure from the forest disregarding cow dung, weeding the fields and so on. After the realization that the newly introduced farming techniques were labor intensive, majority of the participants started backtracking from the commitment which they have settled for with SAT officials. They indicated that the use compost manure has would increase a lot weeds in the fields also taking into consideration that there was no ploughing. They also argued that the soil will be very hard for them to weed properly like they used to do in ploughed grounds. Observations from the research also revealed there was an antagonistic relationship between the interveners and the intended beneficiaries pertaining the best ways of implementing conservation farming. Resultantly, some participants ended up withdrawing from the project regardless of the fact that they have given their commitment and the majority of them have been assisted with free farming implements like seeds and other farming tools like hoes and small ploughs. Arguing from this stand point, one could subscribe to Long's ideas that human beings are not blank slates or tabula rasa; they are reasonable and calculative beings who know what they want and what to do. In this same line of argument, Darendorf (1959) espoused that wherever there are two different categories of people, there is one group which may wish to impose their will on others. However, in the interaction process, the perceived subordinated people will not just tolerate but they fight back leading to the outbreak of conflicts which stands as a bad recipe to the success of the project. In the case of ward 21 of Bikita, it was observed that conflicts emerged between the farmers and SAT officials pertaining to the ways of farming and resulted in majority of the members withdrawing from the newly introduced farming scheme. On the other side of the story, the SAT officials were not happy because the withdrawing members have benefited from free gifts of farming implements. This seems to have built a psychological contract to them that they will see the project to its end whether they can harvest well or not. It is clear that the relationship between farmers and SAT officials was riddled with diametrically opposed mindsets opening the floodgates for serious conflicts.

The research has also revealed that prior to SAT's arrival in ward 21; there was CARE International with the same project of conservation farming. After the fall of SAT's initial attempts of introducing conservation farming just like what Care International did, they 
thought of coming up with a modified approach different from the one which have failed. It was also noted that SAT tried to improve their approach of luring farmers into their projects by providing an avalanche of farming implements, ideas and also favorable conditions for the farming process. After realizing that most of the rural farmers own cattle, zero tillage accompanied by digging was a mammoth task and an unacceptable move by the locals. This explains the strong need for grassroots consultations and participation of the locals so as to make the new farming technologies acceptable and sustainable. Participants of the farming projects expressed that SAT in their renewed approach they accepted tilling of the land but they gave people some small ploughs, relatively smaller than the standard plough. Information obtained from SAT field officers showed that complete abolition of ploughing has created problems and they tried to incorporate their ideas and that minimizing deep ploughing. The use of smaller ploughs could put them somewhere near holes at the same time avoiding too much tempering with the soil. Their argument for this move is largely derived from the scientific observations that soils do not need to be totally disturbed because this would lead to the increased soil disturbance, erosion and etc ( see Gukurume etal, 2010). Regardless of the fact that SAT tried to adopt a participative approach to conservation farming, they were still operating under the principles of scientific discoveries which contradict that of the local farmers. The issue of zero tillage or minimized tilling has caused contradictions and infighting between two different knowledge worlds that is the traditional and the modern knowledge systems. Arguing from this standpoint, Darendorf (1959) envisaged that there is a potential outbreak of conflicts especially in situations where the other group would want to impose their authority and domination others and the subordinated group will therefore respond creating a situation of intense conflicts. In this scenario, the SAT officers are technocrats with the know-how and also vested with potential of plucking out the rural farmers who have been severely affected by perennial droughts. One may observe that sometimes the motive behind interventions best explains that somewhere somehow the affected people might have failed to find solution to the challenges affecting their lives. However, the contestations brought by the variability of knowledge powerhouses on farming have appeared to have opened flood-gates for conflicts and disgruntlement. Overally, such kind conflicts may appear to be too costly to the realization of the projected targets in the farming industry.

During the time of this ethnographic study in ward 21, the researcher also held some transect walks into the participants' fields. He observed that the majority of the people who have participated in conservation farming were not totally subscribing to the exercise. The farmers divided the field into two categories and the bigger position was reserved for their orthodox farming whilst the smaller percentage would be for conservation. Investigating into the cause for this mixed or combined farming, the respondents explored two major reasons. Firstly, they pointed out that they joined the programme in order to get free farming implements and secondly they don't trust new farming techniques while totally disbandling their orthodox farming techniques. The major reason was also that they could not solely rely on new things which they haven't seen before citing strong fears that if conservation farming would totally fail; the SAT officials might disappear to somewhere hence leaving them in a dire condition. The observations in Bikita diametrically oppose the experience of the Hurungwe people as observed by Makwara (2010). He expressed that the local people participated with high levels of enthusiasm and the techniques has been applauded as successful as well as reducing hunger related problems in the area. However, in ward 21 of Bikita the situation was not embracing, there was a cat and mouse relationship characterized by mistrust, fear, disobedience and quarrels between the interveners and the intended beneficiaries. The existence of these conflicts has resulted in stalled progress as far as the realization of bumper harvest is concerned in Bikita rural. These turbulent and conflictious relationships in this area tend to be more or less the same with those observed in Chivi where the people jettisoned conservation farming citing its weaknesses of maximizing their labor input if compared with the orthodox farming (Gukurume et al, 2010).

Farming implements conundrum. After the realization by SAT that the local people has previously fallen out with CARE international on the implementation of conservation, they repackaged the programme with less stringent measures coupled with a lot of farming 
implements. They were availed seeds like sorghum which suits in semi-arid regions, groundnuts, roundnuts, hoes, small ploughs, lime fertilizer just to mention but a few. This was done as a way of attracting more clients. As has been noted above that their relationship with the farmers was suspicious, a lot has been reported to have taken place pertaining the use of these implements. It emerged that a lot of them could divide the field and practice dual farming practice of both conservation farming and the orthodox farming. A lot of people have expressed that they joined the programme with one eye opened and the other closed meaning that they were interested in getting benefits at the same time ignoring the instructions which follows thereafter. The majority of the local farmers diverted these farming inputs to their personal uses ignoring some instructions from the SAT providers. Analyzing these scenarios, one would be tempted to say that Giddens' (1985) ideas of seeing human beings as rational and calculative beings would hold much water. The local farmers calculated that the proclaimed farming methods and requirements were diametrically in opposition with their wishes, experience and indigenous knowledge systems but at the same time they were eager to get receive free farming implements. After the attainment of these farming inputs they clandestinely put them to their personalized uses. However, after being trapped between a hard rock and a hard surface needing free farming inputs and also trying follow the new farming instructions, the farmers in most instances partially practiced it at the same time over relying much with their orthodox farming. A closer inspection will tell that these practices would open floodgates for conflicts and confusion between the two partners hence posing threats to the attainment projected targets set by SAT of reducing perennial food shortages in the peasantry rural community of Bikita.

Also on the issues of farming inputs, the locals were mostly encouraged to use compost manure at the expense of cow dung. They were informed that cow dung was not well in their area because it demands a lot of water hence in the case of Bikita with intermittent rainfall patterns, the manure will cause crops to easily wilt. They preached much about the use of manure compost and fertilizers like lime which are not hot as compared to cattle manure. Even this advice can be considered as noble, lime fertilizer appeared to be beyond the reach of many unemployed rural farmers. On the related note, they complained much about spending more of their energies looking for bush manure.

It has also been observed that the local people complained much siting the fact that the encouragement of using compost manure was burdensome because people need to move around bushes cutting grass, in mountains looking for dry leaves and other decomposing substances to be used in the fields. All these activities are encouraged to be done during the dry season such that at the starting of the season all will be in place for farming. However, a lot of local farmers have observed that this exercise was a backbreaking exercise which left them with no time to rest or having time to partake in other non-farming livelihood activities. After the people have complained about the restless time in the bushes, SAT responded to this disgruntlement by availing free lime fertilizer to the farmers. The introduction of lime fertilizer was not well received by the farmers because historically, people have been used to cow dung as the best available fertilizing agent. The farmers resisted using lime fertilizer basing on the speculations that one the soils are treated with this whitish like powder; they will be worse off than typical sand soils. One of the respondents expressed that, 'makamboinepi fetiraiza yakaita sehupfu kudai ichatikuvadzira minda yedu' (where have you seen fertilizer which looks like mealie meal, it will demage our feilds). The lamenting and fear of farmers over the use of lime fertilizer caused mayhem and backtracking as far as its fully adoption is concerned. They rather opted for manure compost at the expense of the fertilizer. Reading from Darendorf's sentiments, putting different groups of people together is a recipe for disaster because they start to compete for control and power for controlling any proceedings in the process of interaction. In the case of ward 21 of Bikita, the SAT officials argued that lime has been scientifically proven to be good in boosting productivity at the same time without damaging soils as predicted by the local farmers. The antagonistic relationship between these two partners has negatively affected the progression of conservation farming in this area. In this realm, the local people resisted most of the advices by outsiders citing that these moves have ceased to be help but appear as a way of intruding and conquering the local people's space. In the study, the researcher observed that after the 
people has fallen out with the use of lime fertilizer which they have previously taken from SAT they end up using it for cleaning plates, cups and other cutleries. It can be observed that the local farmers experimented with lime fertilizer as a cleaning detergent to their kitchen wares rather than using it as a solution to boost their perennial insufficient yields. As a result, SAT officials were disgraced by these acts because they were taken for granted by the people who have initially tendered their commitment to the newly revolutionized farming techniques. This has also caused a communication breakdown between them and the local farmers. The existence of these social events can also be understood in the works of Darendorf (1959) who expressed that conflicts are endemic in interaction and it stands to be a clear sign that there are some tendencies of some people trying to impose their will on others hence leading to the outbreak of conflicts. Regardless of the fact that the local farmers may be labeled or believed to be victims of ignorance by educated developers, they hold their esteem and anybody who may challenge them directly has got the high probability of not winning that war. They will stand their ground and resist all influences regardless of their considered 'poor' or 'inferior' status. (See Scott, 1985, Long, 1992). This then leaves a critical thinker with a lot of questions about who is knowledgeable and powerful between the educated and resourced donors and the 'uneducated' and 'poor' farmers in living in these precarious climatic conditions. After such problems this then calls for strong need to bring both parties together and try to find a grassroots solution so as to avoid resistance or stalled progress towards newly introduced programs.

SAT intervention and environmental backlash. As has been noted from study there has been the occurrence of conflicts between the interventionists and the intended beneficiaries pertaining to the full implementation of conservation farming. It has also been noted that the new farming programme did not only cause problems on farming but they also extended to environment challenges. One can note that the popularizing of compost fertilizer and lime fertilizer at the detriment of cow dung appears to have increased backlash on the environment. The threat emanate from the fact that people have to move around the bushes and mountains looking grass, dry leaves and other decomposed forest elements so as to prepare composts for manure. It emerged that during the initial stages, participants used to harness dry vegetation elements from the forest but with the movement of time the dry vegetative elements seemed to have been depleted. One participant of conservation farming has expressed that, "nekuwandisa kwataita muno, masango apera saka vanoda mashizha nemauswa vavakutotema zvinyoro izvozvo. (Because of overpopulation in this area, forests are depleted and we now rely on cutting green grass and leaves for compost manure.) Taking a closer look on the above sentiments, it is observable that the vast of lands or forestry where compost manure can be harnessed seemed to have been consumed by the ever increasing need for homesteads and the fields for the rural people. On the same issue one can also observe the strong need for the preservation of grazing lands for domestic animals against the backdrop of increasing populations. As a result of these moves, those farmers without money to buy fertilizers on their own will begin to compete in harnessing green vegetation with the hope of producing compost manure which is largely encouraged at the expense of cattle manure in conservation farming. In the initial stages, some people have religiously followed such instructions with the strong need to boost productivity and improving food security. However, this appeared to have put strenuous pressure on the already threatened environment. In this scenario, it has been learnt that some people who have totally rejected to participate in conservation farming were the first people to complain about the destruction of trees and the grass which could have been left out for other uses by the local people at the same time maintained as grazing lands. Non-participants' expressed that should they leave the grazing lands strictly for animal fodder, they could get manure from goats, sheep and cattle and this could make a balanced equation in the mixed farming enterprise. However, some of the participants without cattle were largely committed because of the psychological contract they have signed with SAT after getting some free farming inputs for conservation farming. As a result, one can observe the emergence of intra-group fighting amongst the villagers about the utilization of the natural resources found in their area. The local farmers were always at loggerheads with each other where one category was crying preserving of forests while the other was calling exploiting the forest for boosting 
conservation farming. (See Hardin, 1968). Arguing from this standpoint one can second Darendorf's ideas that conflicts are pervasive in situation where the people in interaction tend to share different mindsets. This explains that human beings are not just pushovers but they are not always at liberty to subdue their interests to others without doing the cost benefit analysis. In the case of Bikita, the programme has caused extended confusion between identifiably three categories that is the non-participants, the participants and also with SAT officials.

Conservation farming in Bikita should not only be taken as causing socially oriented environmental conflicts between the inhabitants. There are also some scientific problems which may happen to the environment and climatic changes in the long run. Scientifically, it has been observed that overgrazing and vegetation destruction creates a situation of disequilibrium in the ecosystem processes hence opening high chances of desertification and other adverse climatic changes in the long run. This may exacerbates the already existing problems like erratic rainfall patterns, excessive temperatures among other environmental dangers. From this stand point, it can be noted that SAT has brought with it some problems with this new farming technology. However, in as much as Drendorf has been talking much about occurrence of conflicts in interaction processes alone, Coser (1982) expressed that conflicts are not always dangerous to the society, they might work as eye openers to situations where people might have relaxed or failed to see potential threats to their existence.

\section{CONCLUSION}

It has been observed from the study that SAT's philanthropic endeavors of revolutionizing agriculture through conservation farming were not as successful as they might have projected. SAT like their predecessors CARE International has fallen in the same trench when they failed to attract comprehensive participation from the local farmers regardless of the fact that they were facing severe and perennial food shortages. Regardless of SAT's improved approach of providing free farming inputs and moving away from zero tillage failed to bring full satisfaction on the part of the intended beneficiaries. The new farming technology has created inter-group and intra-group conflicts pertaining to how it was to be executed at the same time considering the local farmers conventional way of farming. The local people as a group misrepresented SAT officials by pretending to be seriously committed to the programme but at the same time resisting being over dominated by the outside interveners on the best way of farming. As a result, conservation farming did not only bring social fissures between the locals and SAT officials but this also created environmental challenge. People's activities towards on the environment in effort to create compost manure have created conflicts between the participants as well as straining the environment which was already under pressure from the ever increasing human population. One can take note that people are not as simple as they may appear because they have their life worlds and lived realities. Whenever anybody thought of assisting even the vulnerable people in any form, there is a strong need for grass roots consultations and participation from the intended beneficiaries to make the programme a success. This might work as a solution in curbing problems like the ones which were experienced in Bikita. On the same standpoint, this might help much in making the programme acceptable and sustainable.

\section{REFERENCES}

[1] Ackerman, A. (2009). Can we afford the future? The economics of a warming world. ZED Books, London and New York.

[2] Ellis, F. (2000). Rural livelihoods and Diversity in Developing Countries. Oxford University Press.

[3] Coser, L A. and Rosernberg, B. (eds) (1982), Sociological Theory. Macmillan publishing Co. Inc.

[4] Darhendorf, R. (1959), Class and class conflicts in industrial society. Starnford University Press. 
[5] Giddens, A. (1985). Constitution of Society. Cambridge polity press Oxford.

[6] Gukurume, S. etal, (2010). Conservation Farming and the Food Security-Insecurity Matrix in Zimbabwe: A Case Study of Ward 21 Chivi Rural. Journal of Sustainable Development. Volume 12, No.7, 2010 pp. $39-52$.

[7] Hardin, G. (1968) The Tragedy of the Commons. Science, New Series. Vol 162, N0. 3859.

[8] Kassam, A.H. (2009). Rethinking agriculture. Agriculture for Development 1 (Spring), 29-32. Rothes, UK: Tropical Agriculture Association.

[9] Long, N. (1992). The Multiple Optic of Interface Analysis. Wageningen: Wageningen University, Netherlands.

[10] Makwara, E.C. (2010).Sustainable and Profitable Farming through Conservation Agriculture in Zimbabwe: Prospects, Opportunities and Constraints. Journal of Sustainable Development in Africa, Vol 12 (8) pp. 180-190.

[11] Mwanje J I (2001), Issues in Social Science Research: Social Science Research Methodology Series. OSSREA.

[12] Mintz, S. (1995), Food and its relationship to concepts of power.' In McMichael, P, (eds) Food and Agrarian Orders in the World Economy. Westport Praeger Publishers.

[13] Rukuni M, Eicher C.K \& Blackie (Eds). (2006). Zimbabwe's Agricultural Revolution, Revisited, University of Zimbabwe Publications, Harare.

[14] Scott, J. (1985). Weapons of the weak, everyday forms of peasant resistance: New haven. Chicago: Yale University Press.

[15] Tichivangani, A. (2008). An Analysis of Water Management Performance in Smallholder Irrigation Schemes in Zimbabwe. A dissertation submitted to the Department of Soil Science and Agricultural Engineering in partial fulfillment of the Doctor of Philosophy. University of Zimbabwe. 